ORIGINAL ARTICLE

\title{
Factors Causing Derangement in Hematological Parameters among Malaria Patients: Descriptive Study
}

\author{
AMBER HAROON ${ }^{1}$, HUDA ZAMEER ${ }^{2}$, ANEEQA NAZ ${ }^{3}$, ASGHAR JAVAID, AZRA ${ }^{5}$, RIJA ARIF ${ }^{6}$, SYED ZAHID ALI ${ }^{4}$, TALHA \\ LAIQUE $^{*}$ \\ ${ }^{1}$ Department of Haematology, MMDC Ibne Siena, Hospital, Multan-Pakistan \\ ${ }^{2}$ Department of Haematology, Punjab-Pakistan \\ ${ }^{3}$ Department of Pathology, MMDC, Multan-Pakistan \\ ${ }^{4}$ Department of Microbiology, Nishtar Medical University, Multan-Pakistan \\ ${ }^{5}$ Department of Microbiology, Khyber Medical University, Multan-Pakistan \\ ${ }^{6}$ Department of Pathology, NMU, Multan-Pakistan \\ ${ }^{7}$ Department of Pharmacology, Allama lqbal Medical College, Lahore-Pakistan. \\ Correspondence to: Dr. Talha Laique, Email: talhalaique51@gmail.com, Tel:+92-331-0346682
}

\begin{abstract}
Malaria is a global health issue caused by Plasmodium Falciparum.

Purpose: To determine the effect of age and duration of disease on the derangement in hematological parameters among patients with malaria.

Study Design: Descriptive, cross-sectional.

Methodology: The current project was conducted at department of Department of Hematology, Combined Military Hospital, Multan. Study comprised of 186 subjects suffering from malaria with hematological dearrangements. Blood taken for routine investigations like ICT malaria and CBC to diagnose anemia and low platelet count.

Statistical analysis: The collected data was analyzed by using SPSS version 20. Post-stratification chi-square test was used with $p$-value $<0.05$ as significant.

Results: Patients were with mean age of $41.80 \pm 8.51$ years. Mean duration of disease in our study was $4.91 \pm$ 1.32 days. Out of 186 cases, total plasmodium vivax cases were 127 and the remaining 59 cases were of plasmodium falciparum. Among these 127 cases of plasmodium vivax 20 cases were having anemia and 101 cases had thrombocytopenia.

Conclusion: We concluded that the frequency of derangement in hematological parameter in terms of low platelet count was high in comparison to anemia among enrolled subjects. Low platelet count was significantly linked with age groups.

Key Words: Malaria, Age, Anemia, Platelet Count and Duration of Disease.
\end{abstract}

\section{INTRODUCTION}

Causative agent for malaria is mainly Plasmodium Falciparum thus a major public health issue globally. It is an ancient scourge of humanity. Its prevalence is quite high thus causing around 207 million/year malaria cases resulting into 627,000 deaths. Four species of Plasmodium family have been identified as revealed by literature review. ${ }^{1,2}$

Even in modern era, it is still an endemic disease in many countries globally and it is the the most widespread human parasitic disease having its impact on socioeconomic and public health status. ${ }^{3,4}$ Unfortunately, Pakistan is carrying a high burden of malarial cases and is ranked $6^{\text {th }}$ among high burden countries for malaria and tuberculosis worldwide. ${ }^{5}$ Mortality rate due to plasmodium infection as recorded is approximately 50,000 deaths annually. This disease victimizes mainly young people, children and immune-compromised elderly patients. According to one estimate from 2006-2010, 219 million cases were reported resulting in 60,000 death among young people and children under five years of age. ${ }^{6}$ Plasmodium falciparum and vivax malaria are common vectors in Pakistan causing this big health issue. ${ }^{7}$

This disease usually present with high grade fever, rigors and chills, night sweating and weakness with typical history of mosquito bite. It presenting picture is quite variable due to number of complications like anemia, low platelets, hematuria, jaundice, low cell lines and hepatosplenomegaly. The most important contributing factors for anemia include parasitic infections, chronic inflammatory disorders and genetic disorders. Study from Cameron has documented anemia was $14.08 \%$ in patients with malaria. ${ }^{8}$ One researcher reported that $85.5 \%$ low platelet count in malaria patients as they play a critical role in its pathogenesis. ${ }^{9}$ In the light of above description, we planned current project to stratify anemia and low platelets in terms of age groups and duration of disease.

Objectives: To determine the effect of age and duration of disease on the derangement in hematological parameters among patients with malaria.

\section{METHODOLOGY}

Present study held at Department of Hematology, $\mathrm{CMH}$, Multan from following approval by the Hospital's Ethical Committee. Study comprised of 186 subjects suffering from malaria with hematological de-arrangements. Consent was taken from subjects. Venous sample $(5 \mathrm{ml})$ was taken for routine investigations to diagnose anemia and low platelet count. Both gender patients having age $(20-60$ years $)$ presenting with fever $\geq 101 \mathrm{~F}^{\circ}$ plus positive test with ICT malaria and disease duration should be $<7$ days were included in present study. Known Patients with 
coagulopathy \& bleeding disorders, on anti-malarial drugs within 48 hours and previously diagnosed CNS disorders like multiple sclerosis were excluded.

Statistical Analysis: The collected data was analyzed by SPSS v20. Mean \pm SD was given for age and duration of disease. Parameters like sex, age groups, type of malaria, intake of anti-malarial drugs, anemia and low platelet count were shown as frequencies and percentages. Data were stratified for age and duration of disease. Post-stratification chi-square test was used with $p$-value $<0.05$ as significant as significant.

\section{RESULTS}

General parameters of enrolled patients were presented as frequency and percentage with their respective means \pm SD in table-1.

Table-1: General Characteristics Of All Enrolled Patients

\begin{tabular}{|c|c|c|c|}
\hline Variables & Groups & Frequency & Percentage (\%) \\
\hline \multirow[t]{2}{*}{ Age (years) } & $20-40$ & 93 & 50.0 \\
\hline & $41-60$ & 93 & 50.0 \\
\hline $\begin{array}{r}\text { Mean } \pm \text { SD } \\
\text { (years) }\end{array}$ & \multicolumn{3}{|c|}{$41.80 \pm 8.51$} \\
\hline \multirow{2}{*}{$\begin{array}{l}\text { Duration of } \\
\text { disease } \\
\text { (days) }\end{array}$} & $\leq 3$ & 131 & 70.43 \\
\hline & $>3$ & 55 & 29.57 \\
\hline $\begin{array}{r}\text { Mean } \pm \text { SD } \\
\text { (days) }\end{array}$ & \multicolumn{3}{|c|}{$4.91 \pm 1.32$} \\
\hline \multirow[t]{2}{*}{ Gender } & Males & 101 & 54.3 \\
\hline & Females & 85 & 45.7 \\
\hline \multirow[b]{2}{*}{ Type of malaria } & Vivax & 127 & 68.28 \\
\hline & Falciparum & 59 & 31.72 \\
\hline \multirow{2}{*}{$\begin{array}{l}\text { Intake of anti- } \\
\text { malarial drugs }\end{array}$} & Yes & 115 & 61.83 \\
\hline & No & 71 & 38.17 \\
\hline \multirow[t]{2}{*}{ Anemia } & Yes & 27 & 14.52 \\
\hline & No & 159 & 85.48 \\
\hline \multirow{2}{*}{$\begin{array}{l}\text { Low platelet } \\
\text { count }\end{array}$} & Yes & 142 & 76.34 \\
\hline & No & 44 & 23.66 \\
\hline
\end{tabular}

Results for the stratification of hematological dearrangements with respect to age among 186 enrolled patients was shown in table-2.

Table-2: Stratification of hematological dearrangement with respect to age

\begin{tabular}{|l|l|l|l|l|}
\hline \multicolumn{2}{|c|}{} & $\begin{array}{l}\mathbf{2 0 - 4 0} \\
(\mathbf{n}=93)\end{array}$ & $\begin{array}{l}\mathbf{4 1 - 6 0} \\
(\mathbf{n = 9 3})\end{array}$ & $\begin{array}{l}\text { P- } \\
\text { value }\end{array}$ \\
\hline \multirow{2}{*}{ Anemia } & Yes & 18 & 09 & $\mathbf{0 . 0 6 1}$ \\
\cline { 2 - 4 } & No & 75 & 84 & \\
\hline \multirow{2}{*}{ Low platelet count } & Yes & 77 & 65 & $\mathbf{0 . 0 3 8}^{\star}$ \\
\cline { 2 - 4 } & No & 16 & 28 & \\
\hline
\end{tabular}

*Statistically significant

Results for the stratification of hematological dearrangements with respect to duration of disease among 186 enrolled patients was shown in table-3.

Table-3: Hematological de-arrangement with respect to disease duration

\begin{tabular}{|l|l|l|l|l|}
\hline \multicolumn{2}{|c|}{} & $\begin{array}{l}\mathbf{S} \text { days } \\
(\mathbf{n}=\mathbf{1 3 1})\end{array}$ & $\begin{array}{l}\mathbf{3} \text { days } \\
(\mathbf{n}=\mathbf{5 5})\end{array}$ & P-value \\
\hline \multirow{3}{*}{ Anemia } & Yes & 19 & 08 & $\mathbf{0 . 9 9 4}$ \\
\cline { 2 - 4 } & No & 112 & 47 & \\
\hline \multirow{2}{*}{ Low platelet count } & Yes & 99 & 43 & $\mathbf{0 . 7 0 2}$ \\
\cline { 2 - 4 } & No & 32 & 12 & \\
\hline
\end{tabular}

Results for the stratification of hematological dearrangements with respect to disease vector among 186 enrolled patients was shown in table-4.

Table-4: Hematological de-arrangement with respect to vector

\begin{tabular}{|l|l|l|l|l|}
\hline \multicolumn{2}{|c|}{} & $\begin{array}{l}\text { P.Vivax } \\
\text { (n=127) }\end{array}$ & $\begin{array}{l}\text { P.Falciparum } \\
\text { (n=59) }\end{array}$ & \multirow{2}{*}{ P-value } \\
\hline \multirow{2}{*}{ Anemia } & Yes & 20 & 07 & \multirow{2}{*}{$\mathbf{0 . 4 8 4}$} \\
\cline { 2 - 4 } & No & 107 & 52 & \\
\hline \multirow{2}{*}{$\begin{array}{l}\text { Low platelet } \\
\text { count }\end{array}$} & Yes & 101 & 41 & $\mathbf{0 . 1 3 4}$ \\
\cline { 2 - 4 } & No & 26 & 18 & \\
\hline
\end{tabular}

\section{DISCUSSION}

There are various hematological alterations that occur during the asexual stage of its life cycle characterize malaria. There are number of pathological events like an increased release of inflammatory cytokines, endothelial cell activation and sequestration of parasitized RBCs upon the entrance of $P$. falciparum into RBCs. This ultimately causes increase in secretion of inflammation with morphological de-arrangement in all cell lines.

As recommended by WHO that any suspected case of malaria in all epidemiological settings regardless of age must receive parasitological confirmation of its diagnosis. ${ }^{10}$ "Gold standard" methods include Giemsa stained thick blood films for screening and thin blood films for confirmation of its diagnosis. ${ }^{14}$ Unfortunately, they have limitations like trained staff with well maintained equipment hence unavailable in some malaria endemic communities. ${ }^{11}$

Platelets and coagulation factors are essential components of complex environment. ${ }^{12}$ Many studies have been done in-order to explore the effects of malaria on platelet homeostasis. They showed that development of thrombocytopenia among patients is its major complication mainly depending on parasite species or disease severity. ${ }^{13}$ Research showed that $P$. vivax malaria infection and severe malaria cause severe thrombocytopenia in comparison to other species and uncomplicated malaria. Our results showed that thrombocytopenia was significantly $(P=0.00)$ lower than that of the non-parasitemic group which were in line with previous work. Palpable enlarged spleen is suggestive of increased platelet destruction and reduced platelet lifespan due to it with circulating immune complexes. ${ }^{14}$

Present study showed that anemia was predominantly present in $\mathrm{P}$. falciparum cases in comparison to $\mathrm{P}$. viva. This indicated that it is more associated with $P$. falciparum infection as reported by many studies. ${ }^{15}$ Paradoxical to one study that indicated no significant difference between both groups in terms of anemia. ${ }^{16}$

Limitations: It was a single centre study and we did not perform genetic workup among patients in-order to find the genetic cause.

\section{CONCLUSION}

We concluded that the frequency of derangement in hematological parameter in terms of low platelet count was high in comparison to anemia among enrolled subjects. Low platelet count was significantly linked with age groups. It is therefore clinicians should screen these derangements in hematological parameters among patients with malaria in-order to provide proper management. Hence, suggested 
that this screening should be made a routine in our clinical setups.

Author's contribution: AH\&HZ: Conceptualized the study, analyzed the data, and formulated the initial draft.

AN\&AJ: Contributed to the histomorphological evaluation. A\&RA: Contributed to the analysis of data and proofread the draft.

SZA\&TL: Contributed to the proofreading the manuscript for intellectual content

Acknowledgements: I am thankful to Allah and all my colleagues for their help.

\section{REFERENCES:}

1. Mohammed $\mathrm{H}$, Mindaye $\mathrm{T}$, Belayneh M, Kassa M, Assefa A, Tadesse $M$, et al. Genetic diversity of Plasmodium falciparum isolates based on MSP-1 and MSP-2 genes from Kolla-Shele area, ArbaminchZuria District, southwest Ethiopia. Malar J. 2015;14:73. doi: 10.1186/s12936-0150604-8.

2. Hamid MM, Mohammed SB, El Hassan IM. Genetic Diversity of Plasmodium falciparum Field Isolates in Central Sudan Inferred by PCR Genotyping of Merozoite Surface Protein 1 and 2. N Am J Med Sci. 2013;5(2):95-101.

3. Worku L, Damtie D, Endris M, Getie S, Aemero M. Asymptomatic malaria and associated risk factors among school children in Sanja town, Northwest Ethiopia. Int Scholarly Res Notices. 2014;2014: Article ID 303269. Doi; http://dx.doi.org/10.1155/2014/303269

4. Fançony C, Gamboa D, Sebastião Y, Hallett R, Sutherland C, Sousa-Figueiredo JC, et al.Variouspfert and pfmdr1 genotypes of Plasmodium falciparum cocirculate with $P$. malariae, $P$. ovale spp., and P. vivax in northern Angola. Antimicrob Agents Chemother. 2012 Oct;56(10):5271-7. doi: 10.1128/AAC.00559-12.

5. Maltha J, Guiraud I, Kaboré B, Lompo P, Ley B, Bottieau E, et al. Frequency of severe malaria and invasive bacterial infections among children admitted to a rural hospital in Burkina Faso. PLoS One. 2014;9(2):e89103. doi: 10.1371/journal.pone.0089103.

6. Yaseen M, Ali NH. Frequency and Seasonal Distribution of Plasmodium falciparum and Plasmodium vivax in Children in
Tertiary hospital Karachi - Pakistan. Int J Endorsing Health Sci Res. 2015;3(1):23-5

7. Fazil M. The frequency of various human malaria parasite infections at private clinic in Mardan district of Khyber Pakhtunkhwa: a study of 230 cases of Malaria. Pak Paed J. 2013;37(3):173-6.

8. Takem EN1, Achidi EA, Ndumbe PM. An update of malaria infection and anaemia in adults in Buea, Cameroon. BMC Res Notes. 2010 Apr 30;3:121. doi: 10.1186/1756-0500-3121.

9. Shaikh MA, Ahmed S, Diju IU, Dur-E-Yakta. Platelet count in malaria patients. J Ayub Med Coll Abbottabad. 2011 JanMar;23(1):143-5.

10. Teuscher F, Gatton ML, Chen N, Peters J, Kyle DE, Cheng Q. Artemisinin-induced dormancy in plasmodium falciparum: duration, recovery rates, and implications in treatment failure. J Infect Dis. 2010 Nov 1. 202(9):1362-8.

11. Tozan $Y$, Klein EY, Darley S, Panicker R, Laxminarayan R, Breman JG. Prereferral rectal artesunate for treatment of severe childhood malaria: a cost-effectiveness analysis. Lancet. 2010 Dec 4. 376(9756):1910-5.

12. Amaratunga $\mathrm{C}$, Sreng S, Suon S, et al. Artemisinin-resistant Plasmodium falciparum in Pursat province, western Cambodia: a parasite clearance rate study. Lancet Infect Dis. 2012 Nov. 12(11):851-8.

13. Dondorp AM, Fanello Cl, Hendriksen IC, Gomes E, Seni A, Chhaganlal $1<1$ )- et al Artesunate versus quinine in the treatment of severe falciparum malaria in African children (AQUAMAT): an open-label, randomised trial. Lancet. 2010;376(9753):1647-57.

14. Nath KS, Kumar R, Ahmad GS, Banerjee DI). Ali H. An observation on efficacy' and outcome of artesunate versus quinine therapy in complicated malaria patients: a hospital based study. Int J Recent Sci Res. 2015;6(5):3941-6.

15. World Health Organization. WHO Fact Sheet on Malaria. Fact Sheet No 94. World Health Organization. Available at http://www.who.int/mediacentre/factsheets/fs094/en/print. $\mathrm{html}$. Accessed: June 29, 2007.

16. Bhatt S, Weiss DJ, Cameron E, et al. The effect of malaria control on Plasmodium falciparum in Africa between 2000 and 2015. Nature. 2015 Sep 16. 